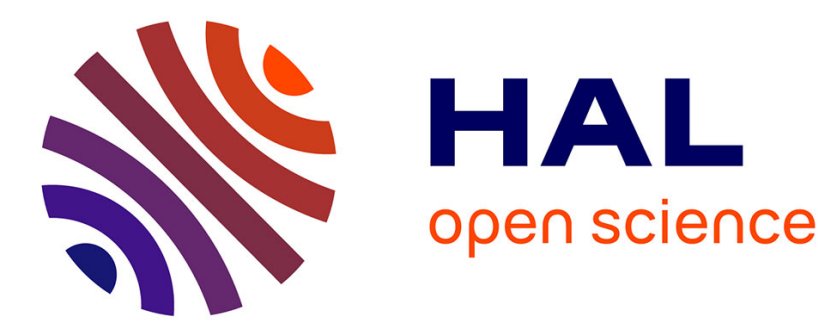

\title{
Identification of clear days from solar irradiance observations using a new method based on the wavelet transform
}

Djelloul Djafer, Abdanour Irbah, Mohamed Zaiani

\section{- To cite this version:}

Djelloul Djafer, Abdanour Irbah, Mohamed Zaiani. Identification of clear days from solar irradiance observations using a new method based on the wavelet transform. Renewable Energy, 2017, 101, pp.347-355. 10.1016/j.renene.2016.08.038 . insu-01394851

\section{HAL Id: insu-01394851 https://hal-insu.archives-ouvertes.fr/insu-01394851}

Submitted on 14 Nov 2016

HAL is a multi-disciplinary open access archive for the deposit and dissemination of scientific research documents, whether they are published or not. The documents may come from teaching and research institutions in France or abroad, or from public or private research centers.
L'archive ouverte pluridisciplinaire HAL, est destinée au dépôt et à la diffusion de documents scientifiques de niveau recherche, publiés ou non, émanant des établissements d'enseignement et de recherche français ou étrangers, des laboratoires publics ou privés. 


\title{
Identification of clear days from solar irradiance observations using a new method based on the wavelet transform
}

\author{
D. Djafer ${ }^{\mathrm{a}}$, A. Irbah ${ }^{\mathrm{b}}$, M. Zaiani ${ }^{\mathrm{a}}$ \\ ${ }^{a}$ Unité de Recherche Appliquée en Energies Renouvelables, URAER, Centre de Devellopement des Energies \\ Renouvelables, CDER, 47133, Ghardaïa, Algeria \\ ${ }^{b}$ Laboratoire Atmosphères, Milieux, Observations Spatiales (LATMOS), CNRS : UMR8190 - Université Paris VI - \\ Pierre et Marie Curie - Université de Versailles Saint-Quentin-en-Yvelines - INSU, 78280, Guyancourt, France
}

\begin{abstract}
A new method using the wavelet transform properties is developed to determine clear days of solar irradiance. These days are needed to model the solar radiation and to compare the existing empirical models. We use this method to process four years of global solar irradiation data collected at the Research Unit of Applied Renewable Energies at Ghardaïa city in Algeria. We also determine clear days from this data set using a standard method based on the clearness index criteria. The results show that the two methods give different numbers of clear days. The effect of this difference is analyzed by computing the Global Solar Radiation (GSR) with the Iqbal C model but also by the estimation of turbidity parameters using for that a innovative approach. We find that some significant differences are observed in the GSR modeling leading to bad estimation of turbidity parameters. We conclude that using our method is therefore more efficient since it is not dependent of the site and observations.
\end{abstract}

Keywords: solar radiation, turbidity parameters, clearness index, wavelet transform.

\section{Introduction}

Solar radiation passing through the Earth atmosphere keeps useful information on the medium. The solar flux is attenuated by scattering, air mass, clouds, aerosols and various reflections. Physical models that explain the solar flux and its temporal variations measured on the ground are of great importance to know the atmosphere state when observing, especially to know the components that are responsible of flux fluctuations. The analysis of these fluctuations is a passive way to probe the atmosphere in contrast to the use of specific instruments such as lidars and radars. Observations during clear days allow detecting certain atmospheric constituents such as aerosols and track their evolution, which may impact Earth's radiative budget and the climate. Clear day observations are also required for models to derive and predict solar irradiance especially

\footnotetext{
* Principal corresponding author

${ }^{* *}$ Corresponding author

Corresponding author

Email addresses: djdjafer@gmail.com (D. Djafer ), air@latmos.ipsl.fr (A. Irbah), zaianimo@gmail.com (M. Zaiani) 
where it cannot be measured. These models are needed to obtain the correct design and output of solar power plants in case of clear sky conditions. This accrued interest comes from the huge investments in solar applications in most of countries where the radiative solar resources need to be accurately characterized either measured or modeled. Validating candidate models for this kind of task is an essential step in the process to provide analysts with sufficient background information on their detailed performance. Several works studying and comparing broad band irradiance models are reported in the literature [12]. These models with high-performance and good accuracy are, as previously mentioned, of great interest for clear sky conditions. To assess the performance and improve the validation of such models it is necessary to have clear sky situations i.e. data free of noise and cloudy periods, to obtain valid performance results [12].

The commonly used tool to characterize sky conditions (classification of day types) over a particular site is the clearness index $k_{t}[2,3,14,16,17,18,22,23,23,26,30]$. On a clear day, the atmosphere causes a reduction of the extraterrestrial solar input by about 30 per cent and to nearly 90 percent in a very turbid (cloudy) day. $k_{t}$ ranging values depend from one author to the other. Alves et al. [2] reported that a cloudy sky corresponds to $0<k_{t} \prec 0.3$, a partially cloudy sky to $0.3 \leq k_{t} \leq 0.65$ and a clear sky to $0.65<k_{t}<1$. The last definition was also adopted by Gueymard [18]. Following Bendt et al. [4], clear sky is when $0.5 \leq k_{t} \leq 0.85$, greater than 0.5 for Ahmed et al. [1] and greater or equal than 0.7 for Molineaux et al. [24], Li and Lam [19], Li et al. [20] and Eftimie [11]. For Iqbal [15], a clear sky is defined when $k_{t}$ ranges between 0.7 and 0.9 while Reindl et al. [29] proposed $k_{t}>0.6$. The clear sky of most tropical regions for Ndilemeni et al. [25] corresponds for $0.68 \leq k_{t} \leq 0.75$. The choice of $k_{t}$ interval values is also different from one site to another according to Mellit et al. [23]. In addition it varies also from day to day and from month to month as stated by Serban [31] and Ahmed et al. [1]. We see clearly that there is no unique limit value of $k_{t}$ neither a direct method for its determination. Therefore, its choice may be controversial to discriminate between clear and turbid days. A bad value will affect the number of clear and turbid days by not selecting the good days. Consequently, the performance of modeling and analysis of solar irradiance data may highly be $k_{t}$ dependent. For this raison, the problem of $k_{t}$ choice is first considered in the present work proposing a method that easily separate clear and cloudy periods. This uses the wavelet transform properties that automatically computes a threshold value to discriminate between clear and turbid days. It is chosen according to the noise level and cloud signature present in the recorded data of solar irradiance. First, we present the algorithm based on the $k_{t}$ mean value of the clearness index to distinguish between a clear and a non clear day. Then, we introduce the wavelet transform method that we compare with the $k_{t}$ mean one considering the number of clear days obtained from five years of data recorded at Ghardaïa city in Algeria [8]. Finally, we base our comparison on the errors induced onto the GSR (Global Solar Radiation) model and in the estimation of turbidity parameters.

\section{The clearness index method to select clear and turbid days}

The clearness index is usually used to determine the clear days to perform model comparison and other studies. It was introduced by Liu and Jordan [22] as a parameter that accounts for stochastic property conditions for a given site [27]. Interval values for the clearness index are used to separate clear and turbid days (see Section 1). They change however from one site to another leading to misinterpretation of the results especially when authors are comparing and studying the clear sky empirical models. We develop then an algorithm based on the instantaneous clearness index to determine automatically complete clear days from a huge data set. The different steps of the algorithm are as follows: 
1. Selection of global solar radiation records of a given day where the Sun elevation is greater than $10^{\circ}$. This restriction is due to the thin haze in the early morning or late afternoon that may be present. This may lead to consider clear days as not, if any.

2. Calculation of the instantaneous clearness index $k_{t}$. It is defined over time $t$ between sunrise and sunset as the ratio between the terrestrial global solar radiation $G$ on a horizontal surface and the extraterrestrial one $G_{0}$. Its mathematical expression is:

$$
k_{t}=\frac{G}{G_{0}}
$$

$G_{0}$ in $W / m^{2}$ is given by [10]:

$$
G_{0}=I_{s c} *\left[1+0.033 \cos \left(\frac{360 N}{365}\right)\right] \times[\cos (\phi) \cos (\delta) \cos (\omega)+\sin (\phi) \sin (\delta)]
$$

where $I_{s c}=1367 \mathrm{~W} / \mathrm{m}^{2}$ is the solar constant and $\mathrm{N}$ the day number in the year $(\mathrm{N}=1$ is the first and $\mathrm{N}=365$ the last day in the year). $\phi, \delta, \omega$ are respectively the latitude of the location, the solar declination angle and the hour angle at Sun rise in degrees.

The data used in this work were collected at the Unit of Applied Research in Renewable Energy (Ghardaïa, Algeria) between (2005-2008). The instruments and methods of the data collection are described in detail in Djafer and Irbah [8]. The key to know is that the three components of solar radiation are recorded every 5 minutes since 2004 together with the temperature and humidity. The instruments that measure the direct, the global and the diffuse solar radiation components are from EKO instruments (http://eko-eu.com/). They are usually cleaned two or three times per week according to the weather conditions. They are also calibrated each three years at the meteorological station of Tamanrasset (latitude $=+22.78^{\circ}$, longitude $=+5.51^{\circ}$, altitude $=$ $1270 \mathrm{~m}$ ) where the solar irradiance is measured since 1970. The histograms of the instantaneous clearness values obtained with these data are shown in Figure 1. Each histogram in the figure is computed over one year for the period 2005 to 2008. The values of the statistical analysis are given in Table 1. We note that the annual mean and median values of $k_{t}$ are 0.67 and 0.73 . We tried several values of $k_{t}$ between 0.68 and 0.74 to select the clear days from the data set and we finally opted for $k_{t}=0.70$ as the optimal limit to define them. We should point out that we may have few days classified as clear with this choose when the clearness index are greater than 0.70 (see upper curves in Figure 2) and other omitted if it is lower (see bottom curves in Figure 2). This is a source of error for the models that use the results coming from this kind of data analysis because of the inefficiency to select the boundary parameter of the clearness index.

\section{Discrimination between clear and turbid days using the wavelet method}

The wavelet transform decomposes signals simultaneously in the time and frequency domains. This allows to better control their main properties and to process the noise. The discrete version of the wavelet transform is implemented with several algorithms among them the $\grave{a}$ trous algorithm [13, 32, 33]. We will use the wavelet transform implemented with the à trous algorithm to automatically detect the signatures of clouds and the noise magnitude in the daily solar irradiance. We chose this algorithm since the transform is known at each decomposition level, its evolution is followed from one scale to the other and it is easy to implement [7, 9]. The decision if we have or not a clear day is taken from the decomposition analysis considering some 
Table 1: Statistics of the instantaneous clearness index over Ghardaïa city from 2005 to 2008.

\begin{tabular}{lllll}
\hline Year & 2005 & 2006 & 2007 & 2008 \\
\hline Mean & 0.67 & 0.67 & 0.67 & 0.68 \\
\hline Standard deviation & 0.17 & 0.16 & 0.17 & 0.16 \\
\hline Median & 0.73 & 0.73 & 0.74 & 0.74 \\
\hline $25^{\text {th }}$ Percentile & 0.61 & 0.60 & 0.61 & 0.62 \\
\hline $50^{\text {th }}$ Percentile & 0.73 & 0.73 & 0.74 & 0.74 \\
\hline $70^{\text {th }}$ Percentile & 0.78 & 0.78 & 0.79 & 0.78 \\
\hline $\begin{array}{l}\text { Semi-Interquartile } \\
\text { deviation }\end{array}$ & 0.09 & 0.09 & 0.09 & 0.08 \\
\hline
\end{tabular}

criterions.

We first start by recalling the principle of the wavelet transform decomposition using the Mexican hat wavelet and the à trous algorithm (see Fig. 3). The first level decomposition of the measured global solar irradiance component (Fig. 3a) generates two signals, which are the approximation and the detail. The first one (Fig. 3b) is a smoothed version of the main signal (low frequencies) while the second one (Fig. 3c) contains the high frequency components. The noise and signature of clouds of the measured global solar irradiance are present in the high frequency components, if any. The same decomposition procedure is repeated on the first level approximation of the signal giving rise to the second approximation and detail (see Fig. $3 \mathrm{~d}$ and Fig. 3e). It is at this second
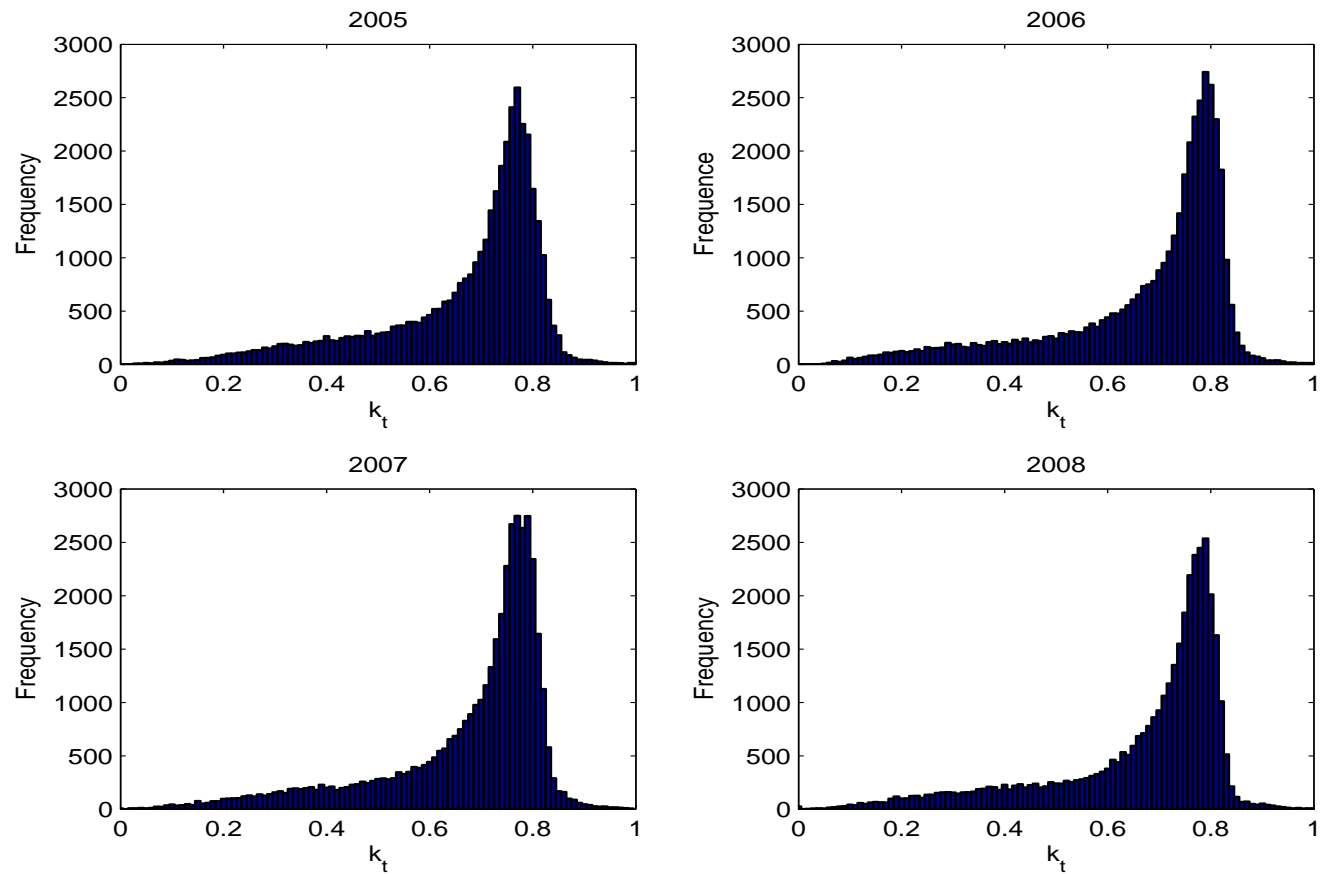

Figure 1: Histogram of the instantaneous clearness index $\mathrm{k}_{t}$ for each year. 

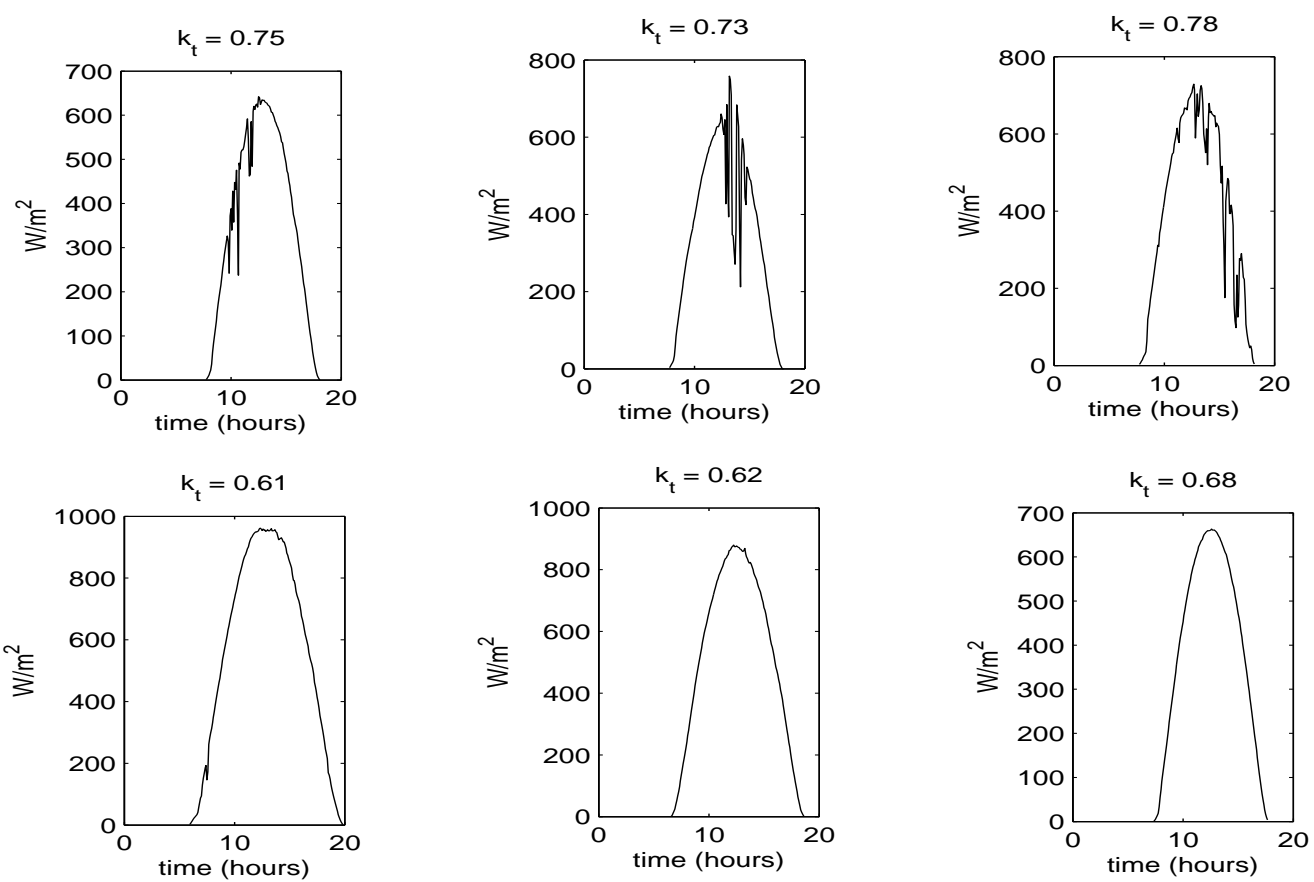

Figure 2: Clear days for $k_{t}<0.7$ and turbid day for $k_{t}>0.7$

level decomposition that the decision is taken if the solar irradiance data of interest correspond to a clear or turbid day. We look if the signal detail values are smaller or larger than a determined threshold (Fig. 3e). This threshold is estimated from the multiresolution decomposition support according to Starck et al. [33] principle. The multiresolution support $M$ of a signal describes in a logical way whether or not a signal $I$ contains information at the time $x$ for a given scale $j$ of the wavelet decomposition. If $M^{I}(j, x)=1$ or is true then $I$ contains information at the time $x$ for the scale $j$. The wavelet transform of a signal with the à trous algorithm produces then a set $w_{j}$ for each scale $j$. The $I_{0}$ original signal can be expressed as the sum of its $I_{p}$ smoothed form and all wavelet coefficients of all $p$ decomposition planes:

$$
I_{0}=I_{p}+\sum_{j=1}^{p} w_{j}
$$

Any value of the signal at $x$ time can be also expressed in the same way as follow:

$$
I_{0}(x)=I_{p}(x)+\sum_{j=1}^{p} w_{j}(x)
$$

The multiresolution support $\mathrm{M}$ will be obtained by detecting the significant coefficients at each scale. It is defined by:

$$
\begin{aligned}
& M(j, x)=1 \text { if } w_{j}(x) \text { is significant } \\
& M(j, x)=0 \text { if } w_{j}(x) \text { otherwise }
\end{aligned}
$$




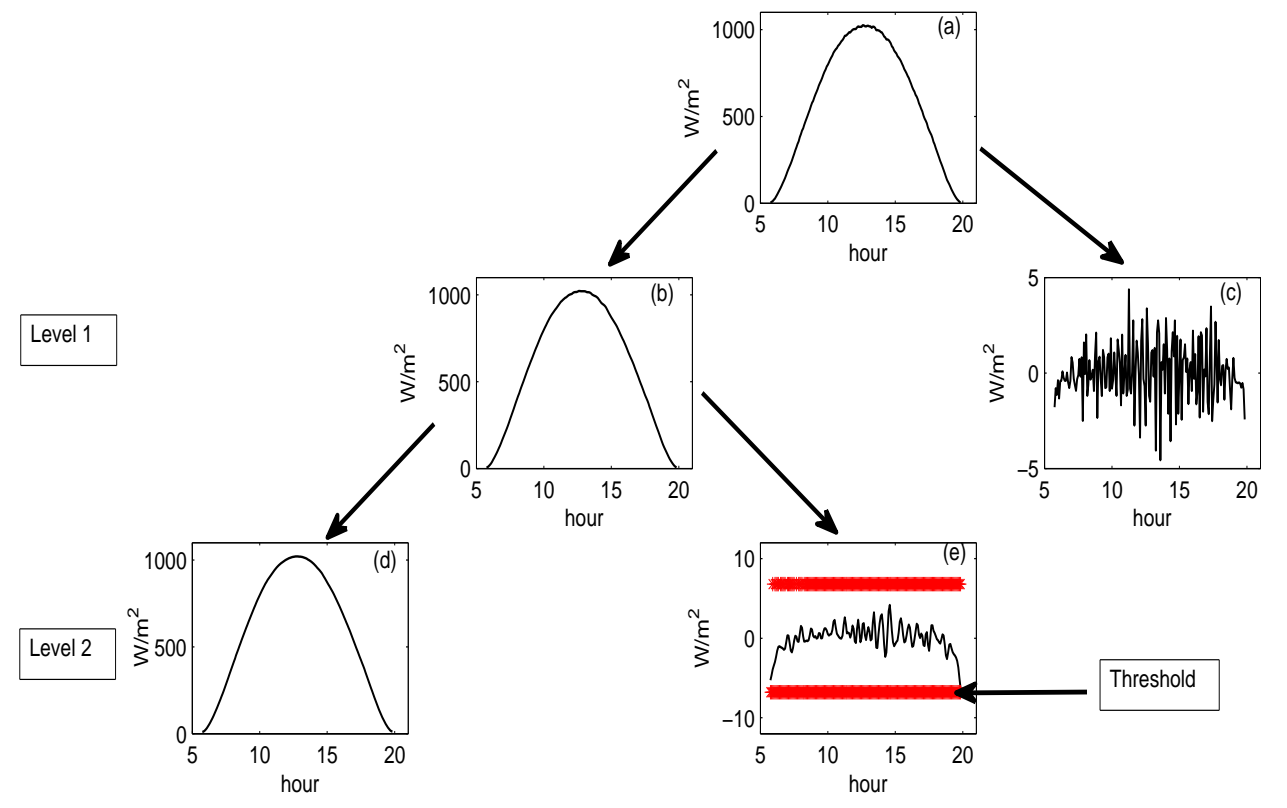

Figure 3: (a) Principle of the wavelet transform decomposition till level 2 of a global solar irradiance component using the à trous algorithm and the Mexican hat wavelet. (b) First approximation and (c) detail of the decomposition. (d) Second approximation and (e) detail of the decomposition with the threshold (red lines) computed with Starck's algorithm.

The algorithm to create the multiresolution support is as follows:

1. We compute the wavelet transform of the signal $I$.

2. We estimate the noise standard deviation at each scale.

3. The binarization at each scale leads to the multiresolution support.

The estimation of the threshold value which is the noise standard deviation $\sigma_{I}$ is then computed by the following iterative steps:

1. We estimate the standard deviation $\sigma_{I}^{0}$ of the noise of the signal $I_{0}$

2. We compute $p$ scales of the wavelet transform of $I_{0}$ with the $\grave{a}$ trous algorithm and then the equation:

$$
I_{0}(x)=c_{p}(x)+\sum_{j=1}^{p} w_{j}(x)
$$

where $w_{j}$ are the wavelet coefficients in each scale and $c_{p}$ is the low frequency part of $I_{0}$. The noise in $c_{p}$ is negligible.

3. We set the iterative step $n$ to 0 .

4. We compute the multiresolution support $M$ which is derived from the wavelet coefficients and from $\sigma_{I}^{n}$.

5. We select the $x$ time values which belong to the set $S: x \in S$ if $M(j, x)=0$ for all $j$ in $1 \ldots p . S$ is the set of $x$ time values, which are only attributed to the noise. 
6. For all the selected $x$ time values, we compute the values $I(x)-c_{p}(x)$ and the standard deviation $\sigma_{I}^{n+1}$ of these values.

7. We increase the iterative step: $n=n+1$.

8. if $\frac{\left|\sigma_{I}^{n}-\sigma_{I}^{n-1}\right|}{\sigma_{I}^{n}}>\epsilon$ (error accuracy) then we go to step 4

This method converges in few iterations giving an estimation of the noise standard deviation, our threshold value. This value obtained for a collected GSR is plotted in Figure $3 e$ together with the second decomposition detail. We have then a clear day if the detail coefficients are less than the constant threshold and it is considered as a turbid day otherwise. The upper curves in Figure 2 show the case of turbid days while clear ones are plotted in the bottom curves in Figure 2.

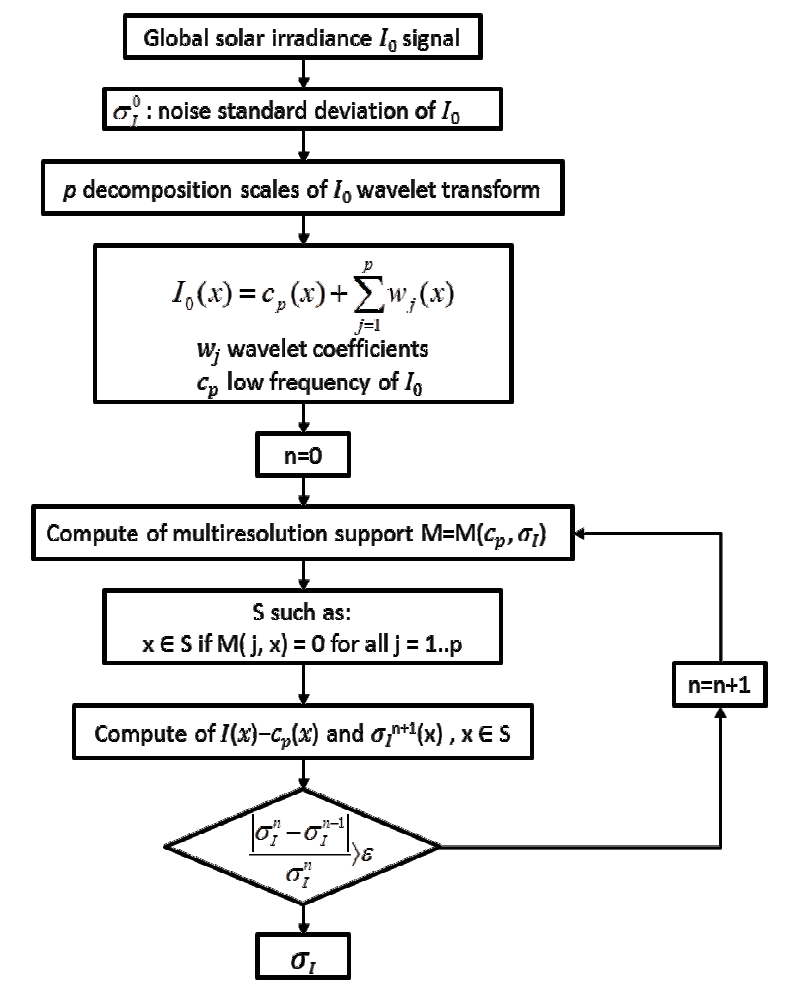

Figure 4: Flowshart for the threshold value estimation to estimate clear days

\section{Comparison of the results obtained from the 2 methods}

We apply the two methods presented in Section 2 and 3 to process the four years (2005-2008) of global solar irradiance data recorded at Ghardaïa. The monthly average number of clear days we find, is plotted in Figure 5 (left curves). We observe that the number of clear days obtained with the wavelet method is in average lower than what we have using the clearness index criteria. 490 clear days are obtained with the wavelet method while we find 623 with the clearness criteria method. A difference of 143 days exists when we process the same whole data set with the 2 

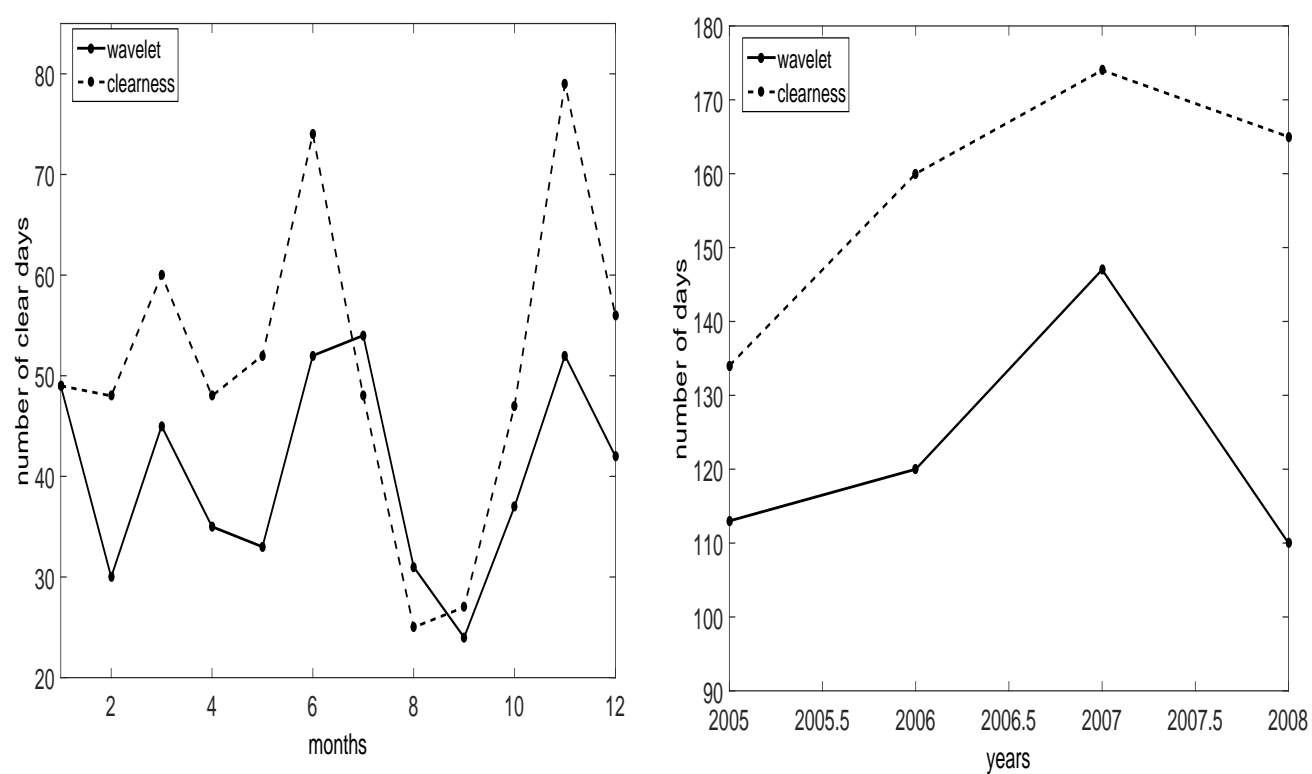

Figure 5: Left curves: Average number of clear days per month for 2005, 2006, 2007 and 2008 obtained with the two methods. Right curve: Number of clear days per year obtained by the two methods.

methods. This difference is significant in statistical studies and of course depends on the limit value of the modified clearness index. The widely used value 0.70 as seen in see Section 2 was taken in our analysis. Since the clearness index method is based on the average of hourly values of the solar irradiance, this makes it very sensitive to the signature of clouds and aerosols. A turbid day may easily classified as clear due to this mean calculation if the signature of clouds and aerosols present in the solar irradiance component is smaller than few tenths of $\mathrm{W} / \mathrm{m}^{2}$. This is confirmed by Lopez and Battles [21] who wrote that some data may erroneously be included as a totaly cloud-free atmosphere if a simple radiometric criterion such as $k_{t}>0.7$ is used. It is then expected that the clearness criteria method is not sensitive for instance to thin cloud covers and cirrus clouds, which have small effects on the measured global irradiance. Our method has the advantage to detect these fluctuations in the global solar irradiance component. The signatures of either cirrus or thin clouds such as shown in Figure 2 will be transformed in distinguishable frequencies of different magnitudes in the detail coefficients as illustrated in the wavelet transform decomposition of Figure 3. Indeed, the day is classified as clear or turbid according to a constant value calculated automatically following the importance of the perturbations. Nevertheless, we observe in Figure 5 that the curves obtained with the two methods have very similar shapes. We note that the number of clear days is lower during months between July and October. The reason is that the sky in the Ghardaiia region is affected by clouds and sandy winds during these months [8]. The number of clear days per year obtained with the two methods is given in Table 2 and plotted in Figure 5 (right curves). The corresponding percentage of clear days relatively to the whole data set is also in Table 2. The first row gives the number and percentage of clear days obtained with the clearness index criteria and the second one using the wavelet method. As before, we observe from the right curves of Figure 5 that the two curves have similar shapes. We note a maximum of clear days in 2007 for the two methods. This confirms previous results of 
Table 2: NB number of clear days per year obtained with the two methods and the corresponding percentage relatively

\begin{tabular}{cllll} 
to the whole data set. & \multicolumn{5}{l}{} \\
\hline Year & 2005 & 2006 & 2007 & 2008 \\
\hline $\begin{array}{c}\text { Clearness index } \\
\text { NB }\end{array}$ & 134 & 160 & 174 & 165 \\
Percentage (\%) & 36.74 & 43.84 & 47.67 & 45.21 \\
\hline Wavelet method & & & & \\
NB & 113 & 120 & 147 & 110 \\
Percentage (\%) & 30.96 & 32.88 & 40.27 & 30.14 \\
\hline
\end{tabular}

the Linke turbidity factor obtained from the same data set [8]. We found that it had a lower value during this year. The annual number of clear days is however relatively constant for the other years when the wavelet method is used while it is not the case for the clearness criteria method.

We finally compute the GSR using the Iqbal $\mathrm{C}$ model, that will be described in the following section, to see how it is impacted by the clear day number estimated by the two methods. We fit with this model each recorded GSR data that corresponds to a clear day. The analysis consists then in the calculation of several fit quality parameters such as the mean absolute error (maee), the root mean squared error (rmsee), the mean absolute relative error (maree), the root mean squared relative error (rmsree), the mean squared relative error (msree), the mean absolute percentage error (mapee), the coefficient of determination (r2) and the correlations coefficient (cf). The values of these parameters are given in Table 3. The wavelet method clearly provides best values for each quality parameter than the clearness index method.

We conclude at this stage that our method is more efficient and is not dependent of the site and observations. We will now analyze in the next Section how the estimation of the turbidity parameters is also affected by the number of clear days used to build the GSR model.

Table 3: The annual average errors (see text for the notation).

\begin{tabular}{clllllllll}
\hline year & maee & rmsee & maree & rmsree & msree & mapee & $r 2$ & $c f$ & method \\
\hline 2005 & 8.786 & 11.479 & 0.021 & 0.035 & 0.002 & 2.081 & 0.995 & 0.998 & Wavelet \\
& 12.196 & 17.004 & 0.031 & 0.060 & 0.011 & 3.075 & 0.991 & 0.996 & index \\
\hline 2006 & 10.929 & 13.696 & 0.026 & 0.045 & 0.004 & 2.590 & 0.994 & 0.998 & Wavelet \\
& 15.316 & 21.532 & 0.044 & 0.093 & 0.026 & 4.353 & 0.983 & 0.992 & index \\
\hline 2007 & 8.525 & 11.030 & 0.020 & 0.035 & 0.002 & 2.010 & 0.997 & 0.999 & Wavelet \\
& 11.855 & 16.920 & 0.031 & 0.061 & 0.011 & 3.080 & 0.987 & 0.994 & index \\
\hline 2008 & 15.519 & 18.504 & 0.039 & 0.060 & 0.008 & 3.931 & 0.957 & 0.997 & Wavelet \\
& 19.247 & 25.240 & 0.050 & 0.095 & 0.022 & 5.001 & 0.946 & 0.992 & index \\
\hline
\end{tabular}

\section{Estimation of the turbidity parameters}

We present first the innovative approach we use to estimate the turbidity parameters with a GSR model. These parameters are the Angstrom coefficient $\beta$, the average surface albedo $\rho_{g}$, the wavelength Angstrom exponent $\alpha$, the forward scatterance $F_{c}$ and the aerosol single scattering albedo $w_{0}$. According to Gueymard [5], the Iqbal $\mathrm{C}$ model offers a better accuracy than the other more conventional models and we will consider it in the following. We first recall hereafter the 
main equations of this model described in detail in Iqbal [15].

The direct normal irradiance $I_{n}\left(\mathrm{~W} / \mathrm{m}^{2}\right)$ is given by:

$$
I_{n}=0.9751 I_{s c} E_{0} \tau_{0} \tau_{g} \tau_{w} \tau_{r} \tau_{a}(\alpha, \beta)
$$

where $\tau_{0}, \tau_{g}, \tau_{w}, \tau_{r}$ and $\tau_{a}(\alpha, \beta)$ are respectively the ozone, gas, water, Rayleigh and aerosol scattering transmittances. $I_{s c}$ and $E_{0}$ are respectively the solar constant and the eccentricity correction factor.

The aerosol scattering transmittance, which depends of the relative optical air mass $m_{a}$, the Angstrom coefficient $\beta$ and wavelength Angstrom exponent $\alpha$, is given by [6]:

$$
\tau_{a}(\alpha, \beta)=(0.12445 \alpha-0.0162)+(1.003-0.125 \alpha)^{-\beta m_{a}(1.089 \alpha+0.5123)}
$$

We are interesting by expressing the global irradiance $I_{t}$ on a horizontal surface, which is the parameter we measure with our instruments. It is the contribution of of 2 irradiance terms:

$$
I_{t}=I_{n h}+I_{d}
$$

where $I_{n h}$ is the normal irradiance on an horizontal plane and $I_{d}$ is the horizontal diffuse irradiance. The normal irradiance $I_{n h}\left(\mathrm{~W} / \mathrm{m}^{2}\right)$ is given by:

$$
I_{n h}=I_{n} \sin (\mathrm{h})
$$

where $h$ is the elevation angle of the Sun in degrees.

The horizontal diffuse irradiance $I_{d}\left(\mathrm{~W} / \mathrm{m}^{2}\right)$ is a combination of the three individual components, which are the Rayleigh $I_{d r}\left(\mathrm{~W} / \mathrm{m}^{2}\right)$ and aerosols $I_{d a}\left(\mathrm{~W} / \mathrm{m}^{2}\right)$ scattering after the first pass through the atmosphere, and the multiple reflection processes $I_{d m}\left(\mathrm{~W} / \mathrm{m}^{2}\right)$ between the ground and sky:

$$
I_{d}=I_{d r}+I_{d a}+I_{d m}
$$

$I_{d r}$ which depends on aerosol single scattering albedo $w_{0}$, is given by:

$$
I_{d r}\left(w_{0}\right)=\frac{0.79}{2} \frac{\tau_{0} \tau_{g} \tau_{w}}{\left(1-\tau_{r}\right)} \frac{I_{s c} \sin (h)}{\left(1-m_{a}+m_{a}^{1.02}\right)} \tau_{a a}
$$

where $\tau_{a a}=\left(1-\left(1-w_{0}\right)\left(1-m_{a}+m_{a}^{1.06}\right)\left(1-\tau_{a}\right)\right.$ is the direct radiation transmittance due to aerosol absorptance.

$I_{d a}$ is related to the forward scatterance $F_{c}$ :

$$
I_{d a}\left(F_{c}\right)=0.79 \tau_{0} \tau_{g} \tau_{w} \tau_{a} F_{c} \frac{\left(1-\tau_{a a}\right)}{\tau_{a a}} \frac{I_{s c} \sin (h)}{\left(1-m_{a}+m_{a}^{1.02}\right)}
$$

$I_{d m}$ related to the ground albedo $\rho_{g}$, is given by:

$$
I_{d m}\left(\rho_{g}\right)=\left(I_{n h}+I_{d r}+I_{d a}\right) \frac{\rho_{g} \rho_{a}}{\left(1-\rho_{g} \rho_{a}\right)}
$$

where $\rho_{a}$ is the albedo of the cloudless sky, which can be computed with:

$$
\rho_{a}=0.0685+\left(1-F_{c}\right)\left(1-\frac{\tau_{a}}{\tau_{a a}}\right)
$$


The $\left(1-F_{c}\right)$ term corresponds to the back-scatterance. The second term on the right hand side of Equation 14 represents the albedo of cloudless skies due to the presence of aerosols, whereas the first term is the albedo of clean air.

The global irradiance $I_{t}$ on a horizontal surface is given by:

$$
I_{t}=I_{n h}+I_{d}=\left(I_{n} \sin (h)+I_{d r}+I_{d a}\right) \frac{1}{1-\rho_{g} \rho_{a}}
$$

We fit the global irradiance component recorded during clear days we extract from the global data set with the Iqbal $\mathrm{C}$ model given by Equation 15 . The method consists to solve a nonlinear fitting problem in the least-squares sense i.e. we look for the $x$-vector coefficients $\left(\beta, \rho_{g}, \alpha, w_{0}, F_{c}\right)$ that minimize the following residual function:

$$
\left\|I_{q b a l}(x)-I_{t r}\right\|^{2}=\sum_{i}\left(I_{q b a l}\left(x_{i}\right)-I_{t r}\right)^{2}
$$

where $I_{t r}$ is the recorded global solar irradiance component and $I_{q b a l}(x)=I_{t}\left(\beta, \rho_{g}, \alpha, w_{0}, F_{c}\right)$ the Iqbal $\mathrm{C}$ model. The result will be a vector $x_{0}=\left(\beta_{0}, \rho_{g_{0}}, \alpha_{0}, w_{00}, F_{c 0}\right)$ that best fits the considered solar irradiance component. The left curve of Figure 6 plots for instance a recorded global solar irradiance component of a clear day superposed to its fit by the Iqbal $\mathrm{C}$ model. We will now apply this process to our whole solar data set to estimate the temporal variations of the turbidity parameters given by the $x$-vector components.

The turbidity parameter we consider first is the $x$-vector component $\beta$, which is the Angstrom coefficient. Its monthly average values during the four years is shown by the right curve in Figure 6. We note that this parameter has maximum values during the summer months and minimum ones in winter. This result confirms what was found and stated in our previous paper [8]. It is explained by a hot summer climate and winds of the south sectors (Sirocco) that characterize the region of Ghardaiia. This kind of winds brings particles of dust and sand with them, which
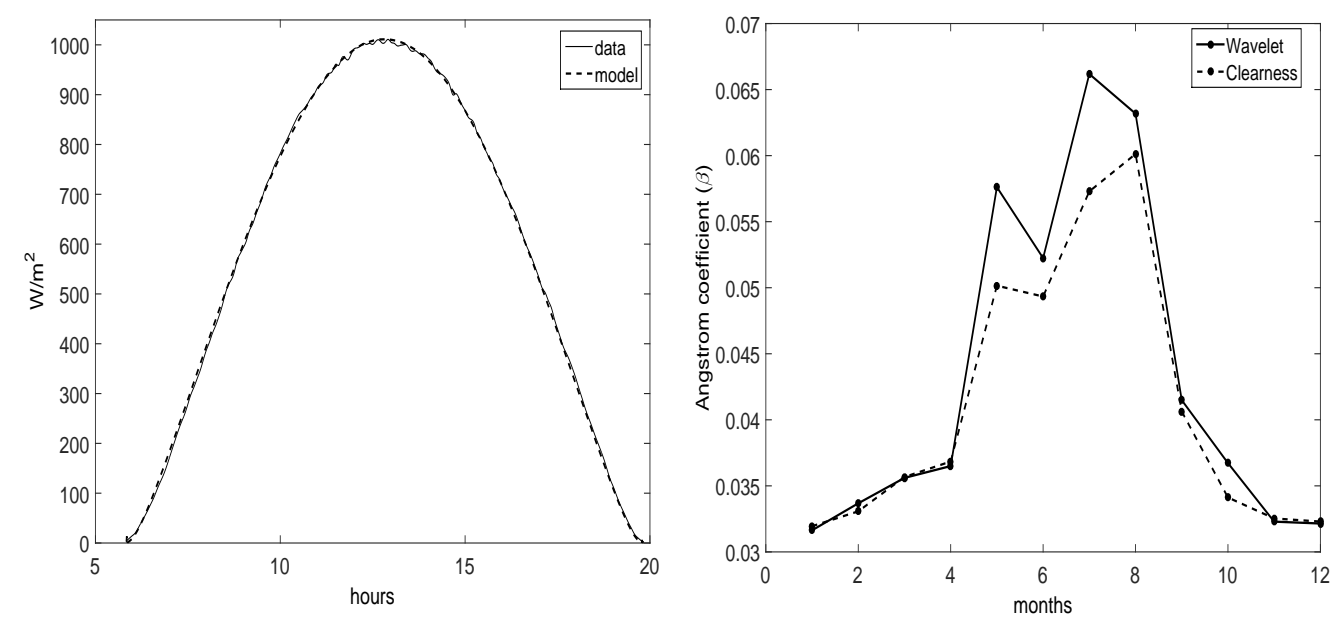

Figure 6: Left curve: A recorded solar irradiance component of a clear day (full line) superposed to its fit obtained with Iqbal C model (dashed line). Right curves: Monthly average of the Angstrom coefficient obtained from Iqbal C model built with clear days obtained from clearness index and wavelet methods. The average is over the four years of solar data. 

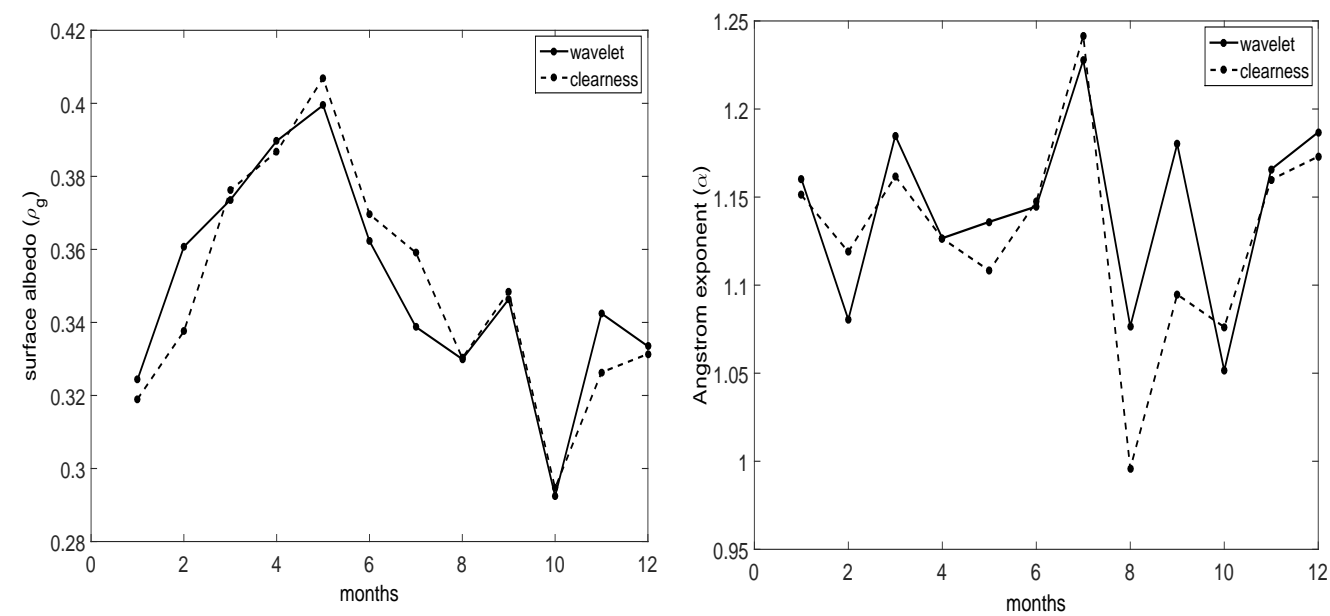

Figure 7: Left curves: Monthly average values of the surface albedo obtained from the Iqbal C model considering clear days obtained from the clearness index criteria and the wavelet methods. The average is over the four years of solar data. Right curve: Monthly average values of the Angstrom exponent $\alpha$ using the same analysis and four years of data.

directly impact the Angstrom coefficient. We also note that the wavelet method gives higher values compared to the clearness criteria one, especially between May and August. The daily difference between the values obtained by the two methods reaches 0.291 whereas it is 0.010 for the monthly difference or about $15 \%$.

The second $x$-vector component we consider is the surface albedo $\rho_{g}$. Its monthly average values computed over the four years are plotted in Figure 7 (left curves). The curves obtained from both methods have similar shapes with locally some differences reaching 0.02 or $5 \%$. The daily difference between the values obtained by the two methods can reaches 0.5 . We observe that the surface albedo has higher values in spring.

The third component of the $x$-vector of the model is the Angstrom exponent $\alpha$. The right curves in Figure 7 show the monthly average values of the Angstrom exponent computed over the four years of solar data. The two methods provide similar results. The mean value of alpha is close to that obtained in 2005 with MODIS data [34]. A small difference of about 5\% is however observed in August and September. The $\alpha$ parameter has high values around July indicating that a relatively high ratio exists between small and large particles of the aerosols [21] in opposite to August. The daily difference between the values obtained with the two methods reaches 2.279 whereas the monthly one is 0.085 .

The monthly average values of the fourth $x$-vector component i.e. the forward scattering parameter $F_{c}$, is plotted in Figure 8 (left curves). The curves representing $F_{c}$ versus time obtained from both methods are very close. We note that the shape of this parameter behaves in an opposite way compared to the Angstrom coefficient $(\beta)$ one. This means that aerosol particles are present when $\beta$ is high and consequently there is weak forward scattering. The daily difference between the values obtained with both methods reaches 0.461 whereas the monthly one is 0.045 .

Finally, The right curves in Figure 8 plot the monthly average values of the aerosol single scattering albedo parameter $w_{0}$, which is the fifth $x$-vector component. We observe also that both curves are very close. $w_{0}$ has the same shape as the Angstrom coefficient $\beta$ in opposite with the forward scattering parameter $F_{c}$. We found that the daily difference between the values obtained 

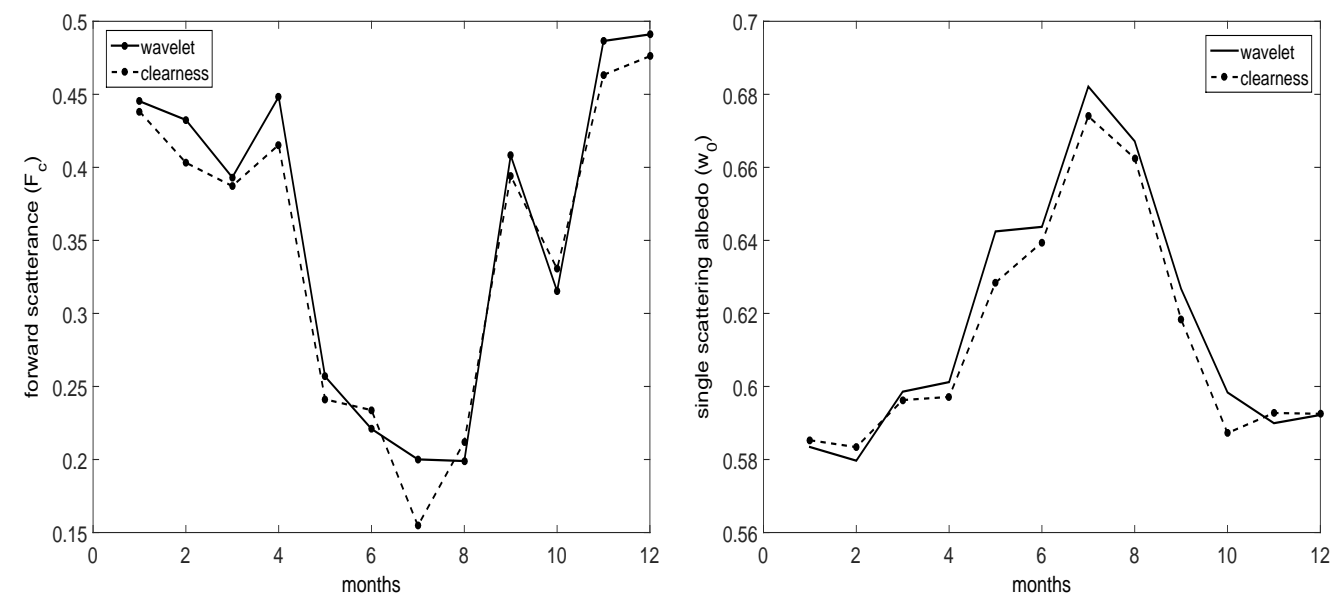

Figure 8: Left curves: Monthly average values over the four years of data of the forward scatterance $\left(F_{c}\right)$ considering the IqbalC model and the clear days obtained with by the clearness index criteria and the wavelet method. Right curve: Monthly average of the aerosol single scattering albedo $\left(w_{0}\right)$ using the same analysis and four years of data.

by the two methods reaches 0.6 whereas the monthly difference is 0.015 .

\section{Conclusion}

A new method is presented in the present work to extract clear observation days from solar irradiance measurements and consequently estimate the turbidity parameters. It is based on the wavelet transform properties and allows the determination of all clear days from a huge data set which are useful for modeling studies. This wavelet method is compared to the well-known one called the clearness index method. The number of clear days found by the two methods differs with 143 days when we process four years of data (2005-2008) of global solar irradiance recorded at the Unit Research of Renewable Energies located in Ghardaïa in the south of Algeria. This difference is highly dependent on the limit value used with the clearness index method. We can point out that we may classify few days as clear with this limit value and other ones as not due to the fixed threshold of $k_{t}$ that depends on the location where measurements are performed. Our method avoid this problem and allows to localize the signatures of noise, aerosols and clouds in time and frequency and then distinguish between clear and turbid days independently of the observation location.

We used in a second step the Iqbal $\mathrm{C}$ model to quantify the effects of the difference of clear days obtained with the two methods. We studied first how the model fits our measurements and secondly we presented a new approach to estimate the turbidity parameters, which are the Angstrom coefficients $(\beta)$, the wavelength exponent $(\alpha)$, the aerosol single scattering albedo $\left(w_{0}\right)$, the forward scatterance $\left(F_{c}\right)$ and the average surface albedo $\left(\rho_{g}\right)$. The statistical analysis revealed that there are some differences between the results to model the GSR and in the estimation of the turbidity parameters. It should be noted that the difference between the two methods could be more significant if another threshold rather than 0.70 was used for the clearness index method. We can conclude that our new method is more efficient and is site independent contrarily to the clearness index method. The other new approach we proposed in this work to estimate the turbidity parameters is also promising and will be used in a near future to study the temporal 
variations of the turbidity parameters at Ghardaiia. Finally, we notify the persons interested by our method that the algorithms of our method are available.

\section{acknowledgements}

We would like to thank and acknowledge the support of the team at the Research Unit on Renewable Energies of Ghardaïa whose collected the data used in the present study.

\section{References}

[1] M. A. Ahmed, F. Ahmad and M. W. Akhtar, 2008. Estimation of Global and Diffuse Solar Radiation for Hyderabad, Sindh, Pakistan. Journal of Basic and Applied Sciences 5, 2, 73-77.

[2] Alves M.d.C., Sanches L., Nogueira J.d.S., Silva V.A.M., 2013. Effects of Sky Conditions Measured by the Clearness Index on the Estimation of Solar Radiation Using a Digital Elevation Model. Atmospheric and Climate Sciences,3, 618-626.

[3] Babatunde, E.B. and Aro, T.O. 1990. Characteristics Variation of Total Solar Radiation at llorin, Nigeria. Nig. J. of Solar Energy. 9:157-173.

[4] Bendt P., Collares-Pereira M. , Rabl A., 1981. The frequency distribution of daily insolation values. Solar Energy, 27,1,1-5.

[5] Christian A. Gueymard, 2012. Clear-sky irradiance predictions for solar resource mapping and large-scale applications: Improved validation methodology and detailed performance analysis of 18 broadband radiative models, Solar Energy, 86, 2145-2169.

[6] Canada J., Pinazo J.M. and Boscá, J.V, 1993. Determination of Angström's turbidity coefficient at Valencia. Renewable Energy 3, 6/7, 621-626.

[7] Djafer D. and Irbah A., 2013. Processing Method effect on Sun Diameter Measurement with Solar Astrolabe. The Astrophysical Journal, 750:46 (5pp)

[8] Djafer D. and Irbah A., 2013. Estimation of atmospheric turbidity over Ghardaa city. Atmospheric Research, 128, 78-84.

[9] Djafer D., Thuillier G., Sofia S., Egidi A.,2008. Processing Method Effects on Solar Diameter Measurements: Use of Data Gathered by the Solar Disk Sextant. Solar Phys. 247:225-248.

[10] Duffie JA. and Beckman WA., 2006. Solar engineering of thermel processes. $3^{\text {rd }}$ ed. New York: Wiley.

[11] Eftimie E., 2013. Beam Horizontal Irradiance Simulation for Bra?ov Urban Area - Clear Sky Model. International Conference on Environmental and Geological Science and Engineering, ISSN: 1790-2769.

[12] Gueymard C.A., 2011. Clear-sky irradiance predictions for solar resource mapping and large-scale applications: Improved validation methodology and detailed performance analysis of 18 broadband radiative models. Solar Energy $86,2145-2169$.

[13] Holschneider M., 1988. On the wavelet transformation of fractal objects. Journal of Statistical Physics 50,5-6,963993.

[14] Ideriah F.J.K., Suleman S.O., 1989. Sky conditions at Ibadan during 1975-1980. Solar Energy,43,6,325-330.

[15] Iqbal, M., 1983. An Introduction to Solar Radiation. Academic Press, Toronto.

[16] Kumar R., Umanand L., 2005. Estimation of global radiation using clearness index model for sizing photovoltaic system. Renewable Energy,2221-2233.

[17] Khem N.P., Binod K.B., Balkrishna S., Berit K., 2012. Estimation of Global Solar Radiation Using Clearness Index and Cloud Transmittance Factor at Trans-Himalayan Region in Nepal. Energy and Power Engineering, 4, 415-421.

[18] Kuye A., Jagtap S.S., 1992. Analysis of solar radiation data for Port Harcourt, Nigeria. Solar Energy,49,2,139-145.

[19] Li DHW., Lam JC., 2001. An analysis of climate parameters and sky condition classifications. Building and Environment,36,435-445.

[20] Li DHW., Lau CCS., Lam JC., 2004. Overcat sky conditions and luminance distribution in Hong Kong. Building and Environment,39,101-108.

[21] G.Lópze and F.J. Battles. 2004. Estimate of the atmopsheric turbidity from three broad-band solar radiation algorithms. A comparative study. 2004. Annals Giophysicae, 22, 2657-2668.

[22] Liu B.Y.H, Jordan R.C. 1960. The interrelationship and characteristic distribution of direct, diffuse and total solar radiation. Solar Energy 4: 1-19.

[23] Mellit A. , Kalogirou S.A., Shaari S., Salhi H., Hadj Arab A., 2008. Methodology for predicting sequences of mean monthly clearness index and daily solar radiation data in remote areas: Application for sizing a stand-alone PV system. Renewable Energy,33, 1570-1590. 
[24] Molineaux, B., Ineichen, P., Delaunay, J. J., 1995. Direct luminous efficacy and atmospheric turbidity - improving model performance. Solar Energy, 55, 125-137.

[25] Ndilemeni, C.C, Momoh, M. and Akande J.O., 2013. Evaluation of clearness index of Sokoto Using Estimated Global Solar Radiation. Journal of Environmental Science, Toxicology and Food Technology, 5, 51-54.

[26] Okogbue E.C., Adedokunb J.A., Holmgrenc B., 2009. Review Hourly and daily clearness index and diffuse fraction at a tropical station, Ile-Ife, Nigeria. International Journal Of Climatology 29: 1035-1047.

[27] A. Peled, J. Appelbaum, 2013.Evaluation of solar radiation properties by statistical tools and wavelet analysis. Renewable Energy, 59, 30-38.

[28] Pinazo J.M., Canada J. and Boscá J.V., 1995. A new method to determine the Angström's turbidity coefficient: its application to Valencia. Solar Energy 54, 4, 219-226.

[29] Reindl DT., Beckman WA. and Duffie JA., 1990. Diffuse fraction correlation. Solar Energy 45, 1-7.

[30] Santos J.M., Pinazo J.M., Caada J., 2002. Methodology for generating daily clearness index index values $K_{t}$ starting from the monthly average daily value . Determining the daily sequence using stochastic models. Renewable Energy,28,10, 1523-1544.

[31] Serban C. , 2009. Estimating Clear Sky Solar Global Radiation Using Clearness Index, for Brasov Urban Area. International Conference on Maritime and Naval Science and Engineering, ISSN: 1792-4707.

[32] Shensa M., 1992. The discrete wavelet transform: wedding the à trous and Mallat algorithms . Signal Processing, IEEE Transactions on (Volume:40, Issue: 10).

[33] Starck J.L., Murtagh F., Bijaoui A., 1998. Image Processing and Data Analysis: The Multiscale Approach. Hardback and softback, ISBN 0-521-59084-1 and 0-521-59914-8.; 300-pp.

[34] Zaiani M., Djafer D., 2013. Atmospheric Turbidity Study Using Ground and Orbit Data. International Journal of Latest Research in Science and Technology, 3,2, 12-18. 